\title{
Enhanced Permanganate Oxidation of Sulfamethoxazole and Removal of Dissolved Organics with Biochar: Formation of Highly Oxidative Manganese Intermediate Species and in-situ Activation of Biochar
}

Shi-Qi Tian ${ }^{1}$, Lu Wang ${ }^{1 *}$, Yu-Lei Liu ${ }^{2}$, Tao Yang ${ }^{1}$, Zhuang-Song Huang ${ }^{1}$, Xian-Shi Wang ${ }^{1}$, Hai-Yang $\mathrm{He}^{1}$, Jin Jiang ${ }^{1}$, Jun $\mathrm{Ma}^{1 *}$

${ }^{1}$ State Key Laboratory of Urban Water Resource and Environment, School of Environment, Harbin Institute of Technology, Harbin 150090, China

${ }^{2}$ Technology $R$ \& D Center for Environmental Engineering, Dongguan University of Technology, Dongguan 523808, China

${ }^{*}$ Corresponding authors:

*Lu Wang, Phone/ Fax: 86451 86283010; e-mail: wanglu9195@,163.com;

*Jun Ma, Phone/ Fax: 86451 86283010; e-mail: majun@hit.edu.cn;

Pages: 15

Figures: 14 


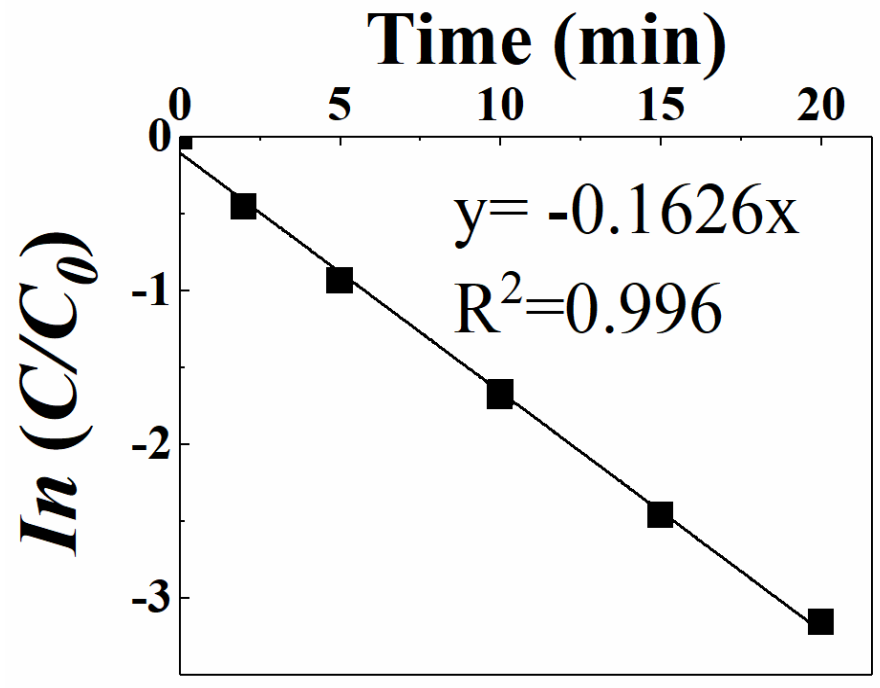

Figure S1. Reaction dynamic about $\mathrm{KMnO} 4$ oxidation of SMX in the presence of biochar. The reaction rates were fitted with pseudo-first-order kinetics law. Experimental condition: $[\mathrm{SMX}]_{0}=10 \mu \mathrm{M},\left[\mathrm{KMnO}_{4}\right]_{0}=100 \mu \mathrm{M},[\text { biochar }]_{0}=50 \mathrm{mg} / \mathrm{L}$, solution $\mathrm{pH}=7.0, \mathrm{~T}=25^{\circ} \mathrm{C}$. 


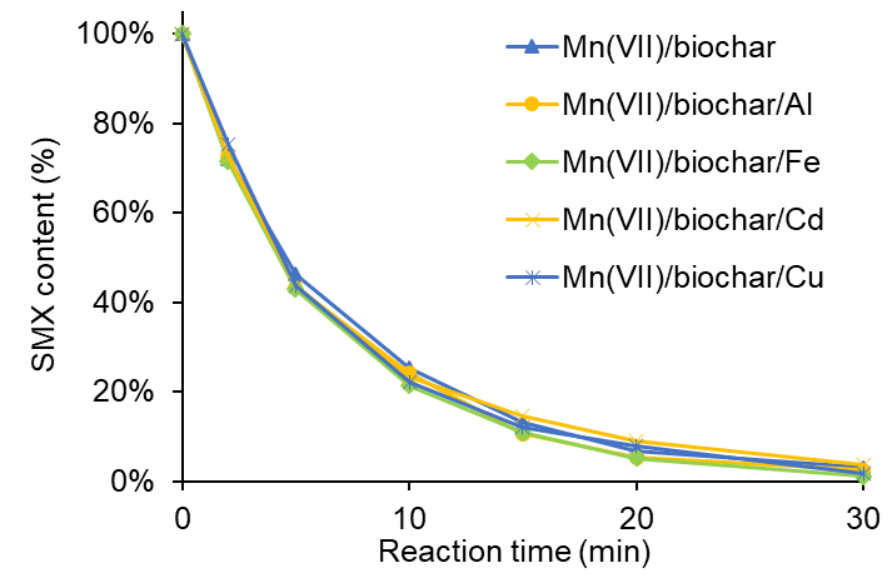

Figure S2. Effects of cations on the $\mathrm{KMnO}_{4}$ oxidation of SMX with the presence of biochar. Experimental condition: $[\mathrm{SMX}]_{0}=10 \mu \mathrm{M},\left[\mathrm{KMnO}_{4}\right]_{0}=100 \mu \mathrm{M}$, [biochar $]=$ $50 \mathrm{mg} / \mathrm{L}$, solution $\mathrm{pH}=7.0, \mathrm{~T}=25^{\circ} \mathrm{C}$. 


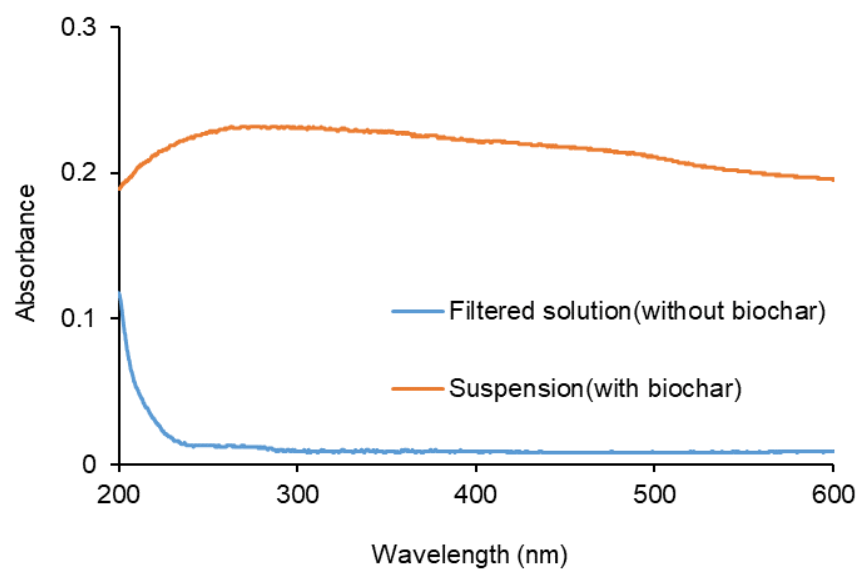

Figure S3. UV-visible spectrum of SMX solution samples with and without biochar. Experimental condition: $[\mathrm{SMX}]_{0}=10 \mu \mathrm{M}$, [biochar $]=50 \mathrm{mg} / \mathrm{L}$, solution $\mathrm{pH}=7.0, \mathrm{~T}$ $=25{ }^{\circ} \mathrm{C}$. 


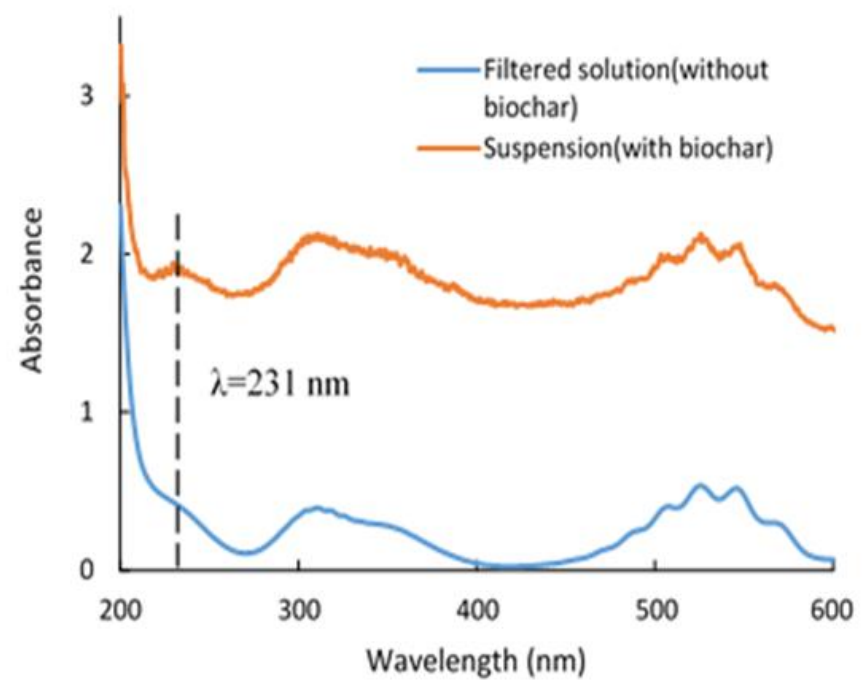

Figure S4. UV-visible spectrum of $\mathrm{KMnO}_{4} /$ biochar solution with the presence of $5 \mathrm{mM}$ of pyrophosphate. Experimental condition: $[\mathrm{SMX}]_{0}=10 \mu \mathrm{M},\left[\mathrm{KMnO}_{4}\right]_{0}=100 \mu \mathrm{M}$, $[$ biochar $]=50 \mathrm{mg} / \mathrm{L}$, solution $\mathrm{pH}=7.0, \mathrm{~T}=25^{\circ} \mathrm{C}$. 


\section{Summary Report}

\section{Surface Area}

Single point surface area at $\mathrm{P} / \mathrm{Po}=0.200213513: 83.4812 \mathrm{~m}^{2} / \mathrm{g}$

BET Surface Area: $86.3203 \mathrm{~m}^{2} / \mathrm{g}$

Langmuir Surface Area: $119.7877 \mathrm{~m}^{2} / \mathrm{g}$

t-Plot Micropore Area: $5.2251 \mathrm{~m}^{2} / \mathrm{g}$

t-Plot External Surface Area: $81.0952 \mathrm{~m}^{2} / \mathrm{g}$

BJH Adsorption cumulative surface area of pores between $17.000 \AA$ and $3000.000 \AA$ diameter: $91.447 \mathrm{~m}^{2} / \mathrm{g}$

BJH Desorption cumulative surface area of pores between $17.000 \AA$ and $3000.000 \AA$ diameter: $99.3645 \mathrm{~m}^{2} / \mathrm{g}$

\section{Pore Volume}

Single point adsorption total pore volume of pores less than $642.330 \AA$ diameter at P/Po $=0.968940516: 0.260884 \mathrm{~cm}^{3} / \mathrm{g}$

t-Plot micropore volume: $0.001679 \mathrm{~cm}^{3} / \mathrm{g}$

BJH Adsorption cumulative volume of pores between $17.000 \AA$ and $3000.000 \AA$ diameter: $0.611195 \mathrm{~cm}^{3} / \mathrm{g}$

BJH Desorption cumulative volume of pores between $17.000 \AA$ and $3000.000 \AA$ diameter: $0.609884 \mathrm{~cm} 3 / \mathrm{g}$

\section{Pore Size}

Adsorption average pore width (4V/A by BET): $120.8913 \AA$

BJH Adsorption average pore diameter (4V/A): $267.345 \AA$

BJH Desorption average pore diameter (4V/A): $245.514 \AA$

Figure S5. BET analysis results about surface area, pore volume and pore size of raw biochar. 


\section{Summary Report}

\section{Surface Area}

Single point surface area at $\mathrm{P} / \mathrm{Po}=0.200164713: 110.1578 \mathrm{~m}^{2} / \mathrm{g}$

BET Surface Area: $114.0993 \mathrm{~m}^{2} / \mathrm{g}$

Langmuir Surface Area: $158.3274 \mathrm{~m}^{2} / \mathrm{g}$

t-Plot Micropore Area: $9.0723 \mathrm{~m}^{2} / \mathrm{g}$

t-Plot External Surface Area: $105.0270 \mathrm{~m}^{2} / \mathrm{g}$

BJH Adsorption cumulative surface area of pores between $17.000 \AA$ and $3000.000 \AA$ diameter: $114.226 \mathrm{~m}^{2} / \mathrm{g}$

BJH Desorption cumulative surface area of pores between $17.000 \AA$ and $3000.000 \AA$ diameter: $122.1714 \mathrm{~m}^{2} / \mathrm{g}$

Single point adsorption total pore volume of pores less than $712.048 \AA$ diameter at $\mathrm{P} / \mathrm{Po}=0.972052192: 0.355954 \mathrm{~cm}^{3} / \mathrm{g}$ t-Plot micropore volume: $0.003032 \mathrm{~cm}^{3} / \mathrm{g}$

BJH Adsorption cumulative volume of pores between $17.000 \AA$ and $3000.000 \AA$ diameter: $0.644809 \mathrm{~cm}^{3} / \mathrm{g}$

BJH Desorption cumulative volume of pores between $17.000 \AA$ and $3000.000 \AA$ diameter: $0.643340 \mathrm{~cm}^{3} / \mathrm{g}$

\section{Pore Size}

Adsorption average pore width (4VIA by BET): $124.7876 \AA$

BJH Adsorption average pore diameter (4V/A): $225.801 \AA$

BJH Desorption average pore diameter (4V/A): $210.635 \AA$

Figure S6. BET analysis results about surface area, pore volume and pore size of used biochar (reacted with $\mathrm{KMnO}_{4}$ ) in the experiment. 

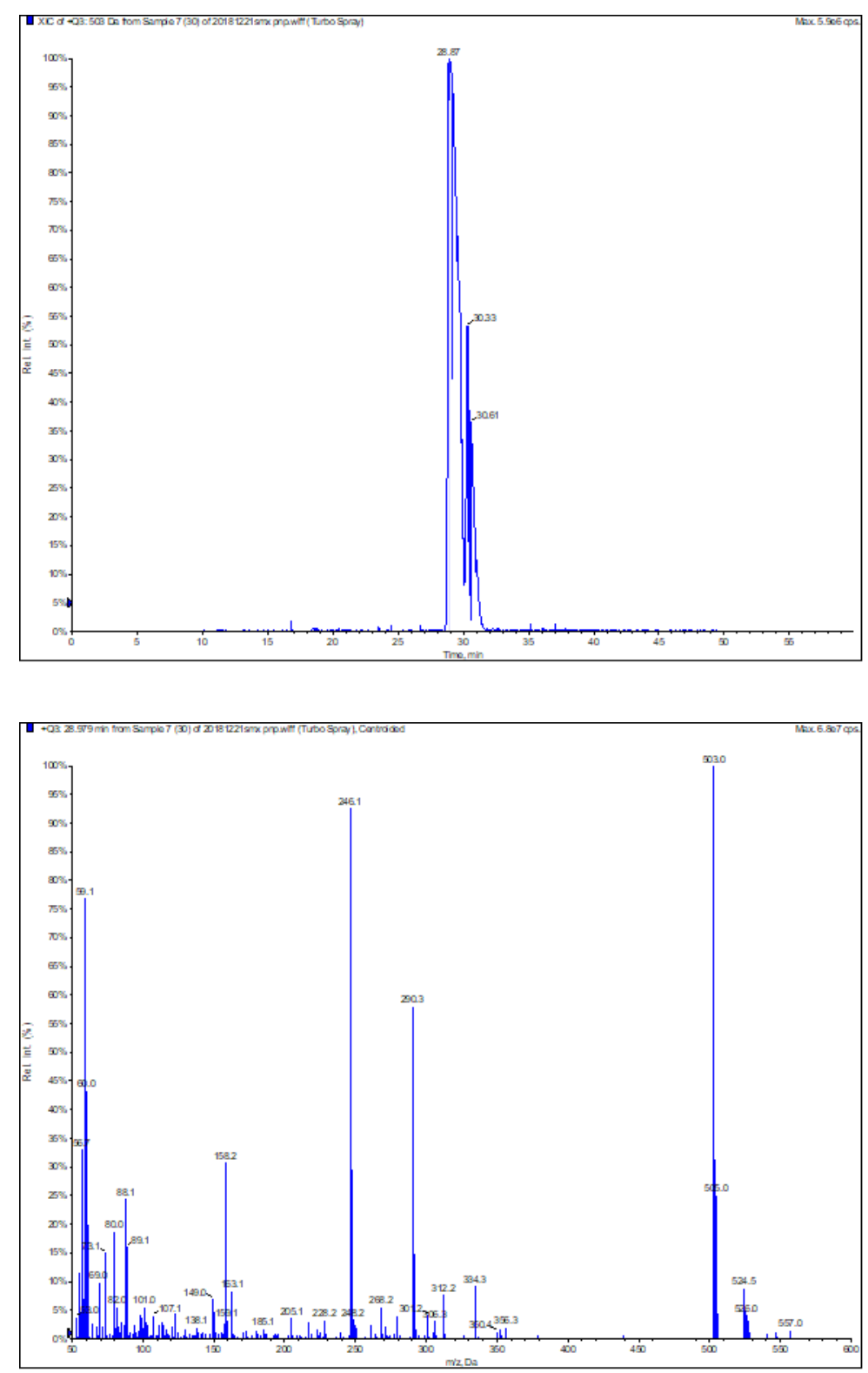

Figure S7. HPLC chromatogram and Mass spectrum of TP 503 identified by HPLC/ESI-QQQ under positive mode in the KMnO4 oxidation of SMX with the presence of biochar. 

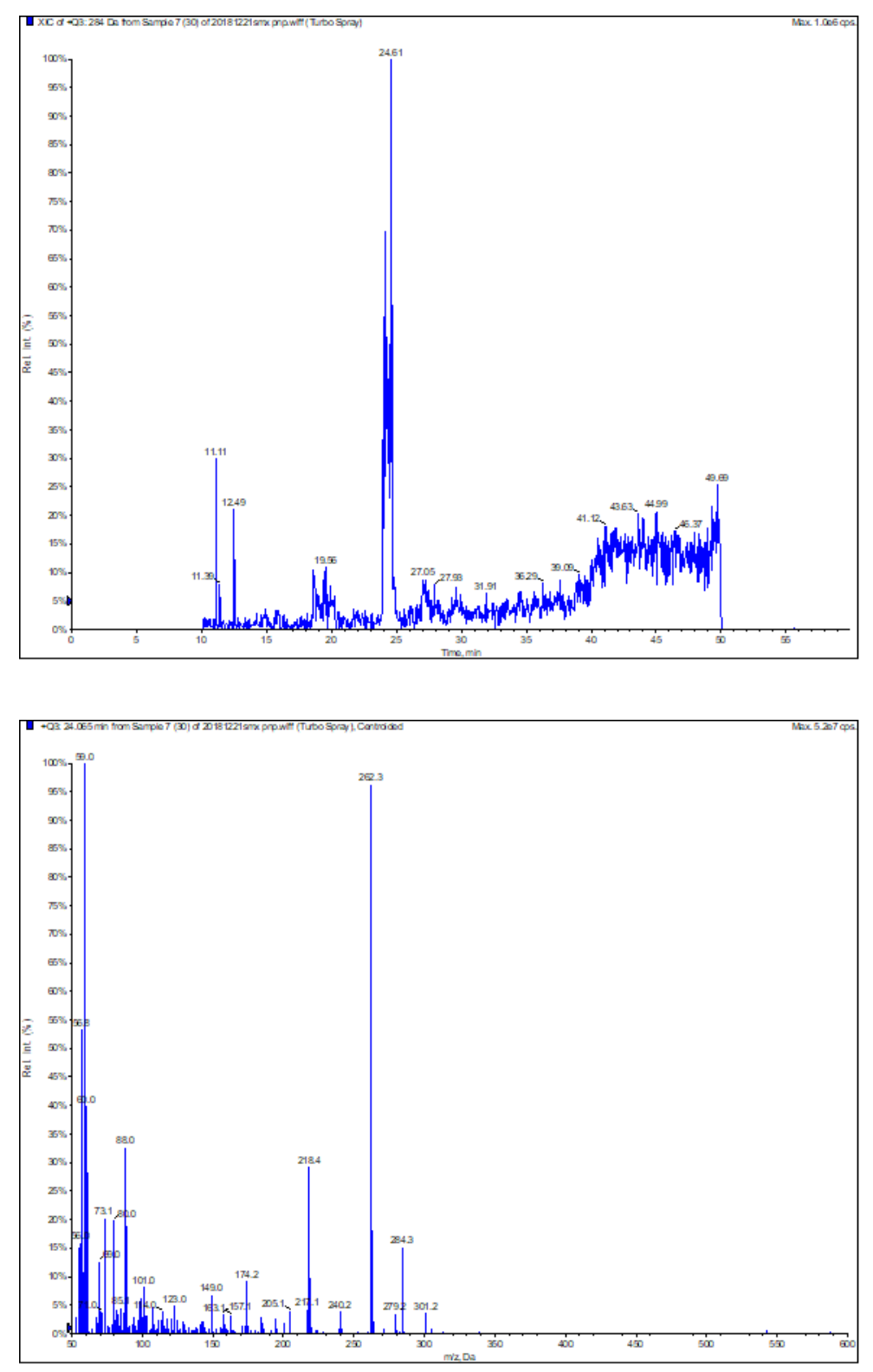

Figure S8. HPLC chromatogram and Mass spectrum of TP 284 identified by HPLC/ESI-QQQ under positive mode in the KMnO4 oxidation of SMX with the presence of biochar. 

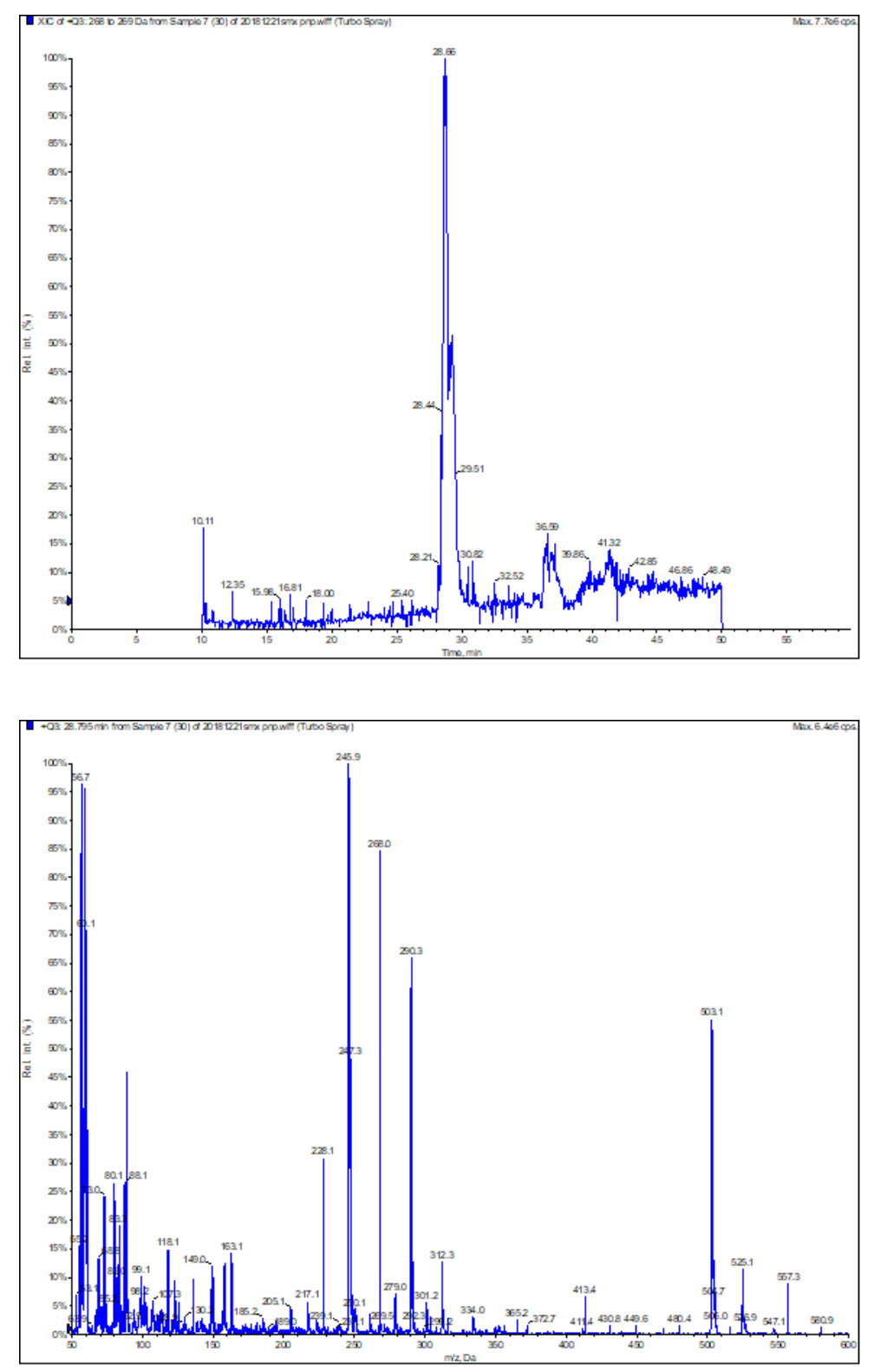

Figure S9. HPLC chromatogram and Mass spectrum of TP 268 identified by HPLC/ESI-QQQ under positive mode in the KMnO4 oxidation of SMX with the presence of biochar. 

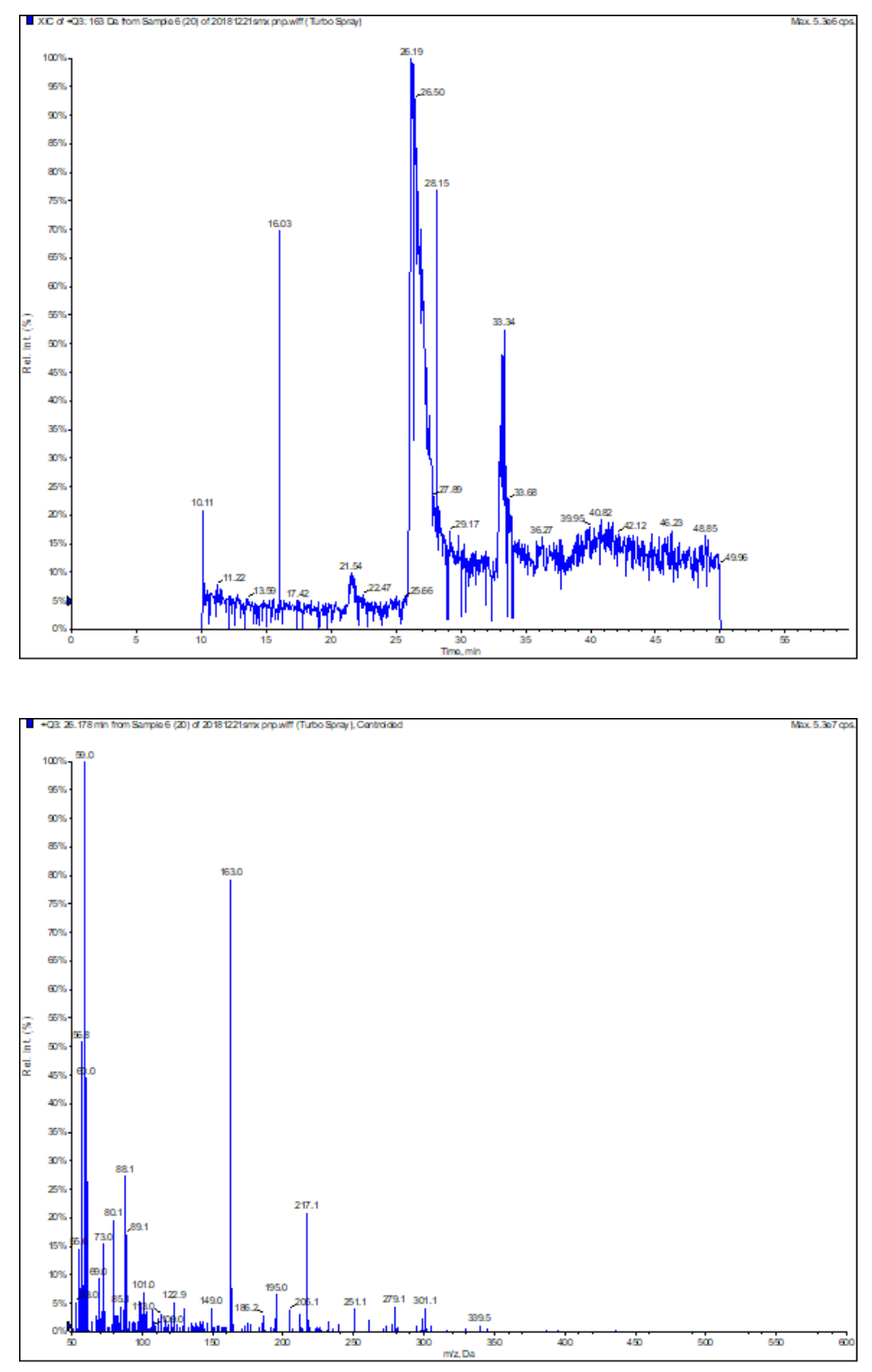

Figure S10. HPLC chromatogram and Mass spectrum of TP 163 identified by HPLC/ESI-QQQ under positive mode in the KMnO4 oxidation of SMX with the presence of biochar. 

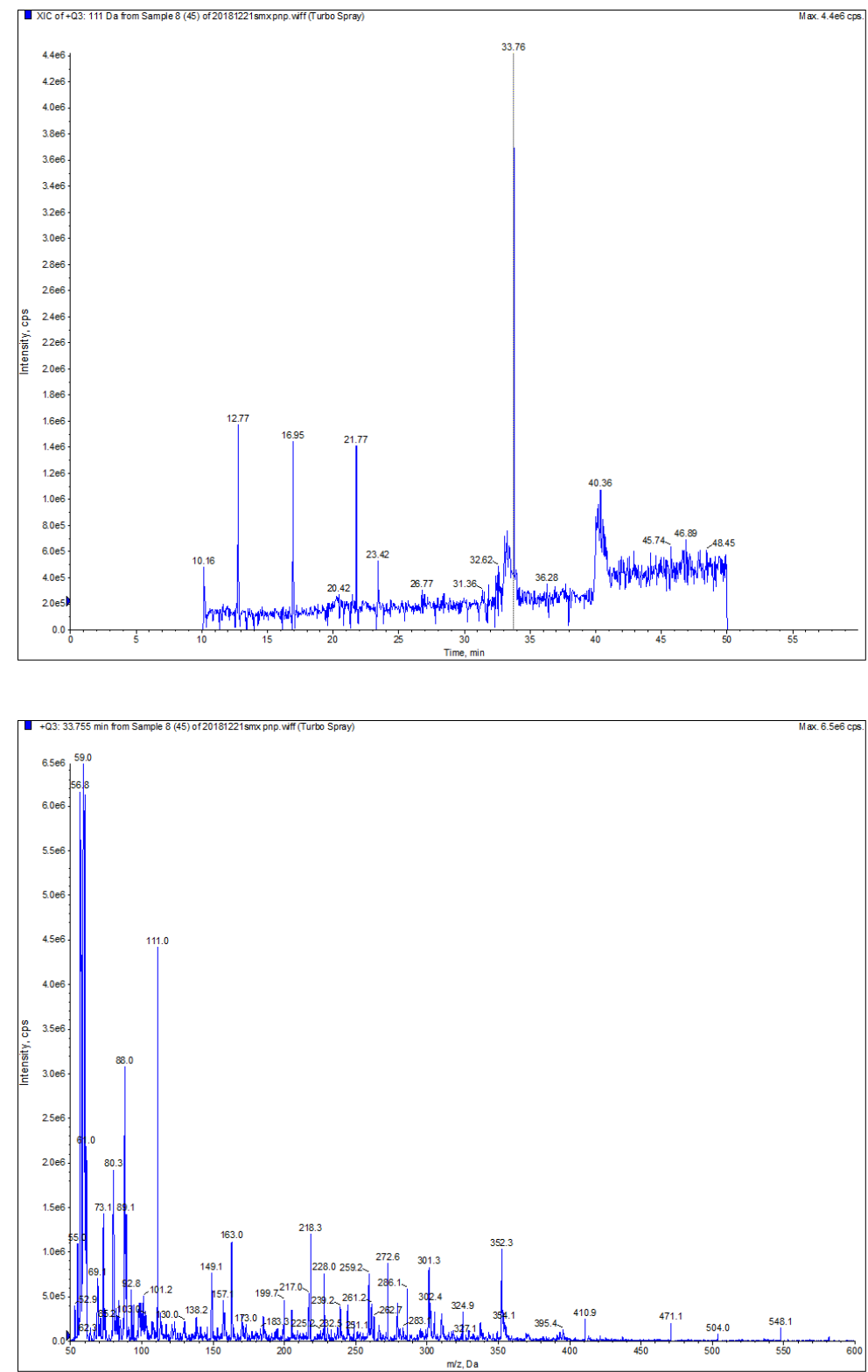

Figure S11. HPLC chromatogram and Mass spectrum of TP 110 identified by HPLC/ESI-QQQ under positive mode in the KMnO4 oxidation of SMX with the presence of biochar. 

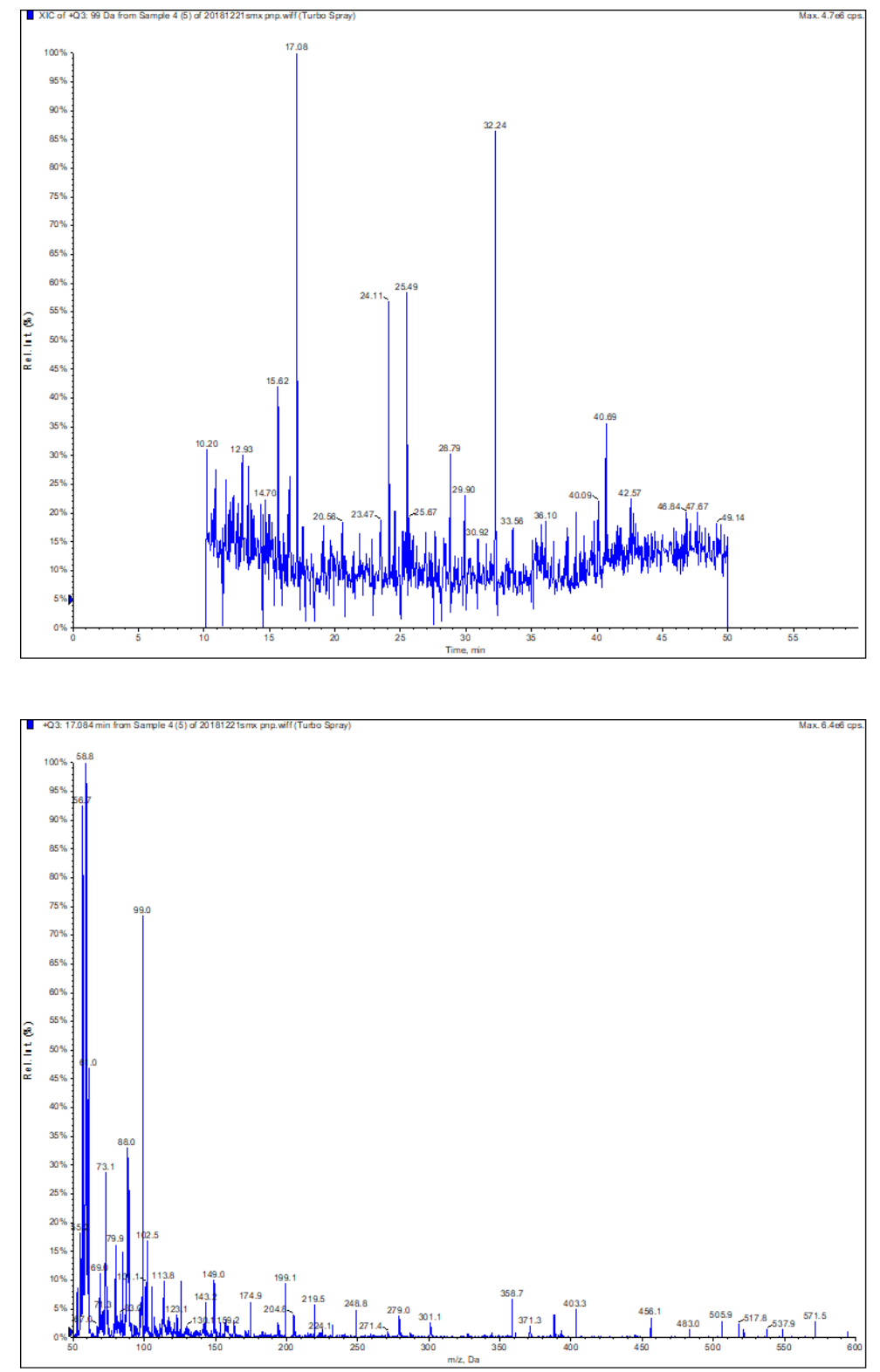

Figure S12. HPLC chromatogram and Mass spectrum of TP 99 identified by HPLC/ESI-QQQ under positive mode in the KMnO4 oxidation of SMX with the presence of biochar. 

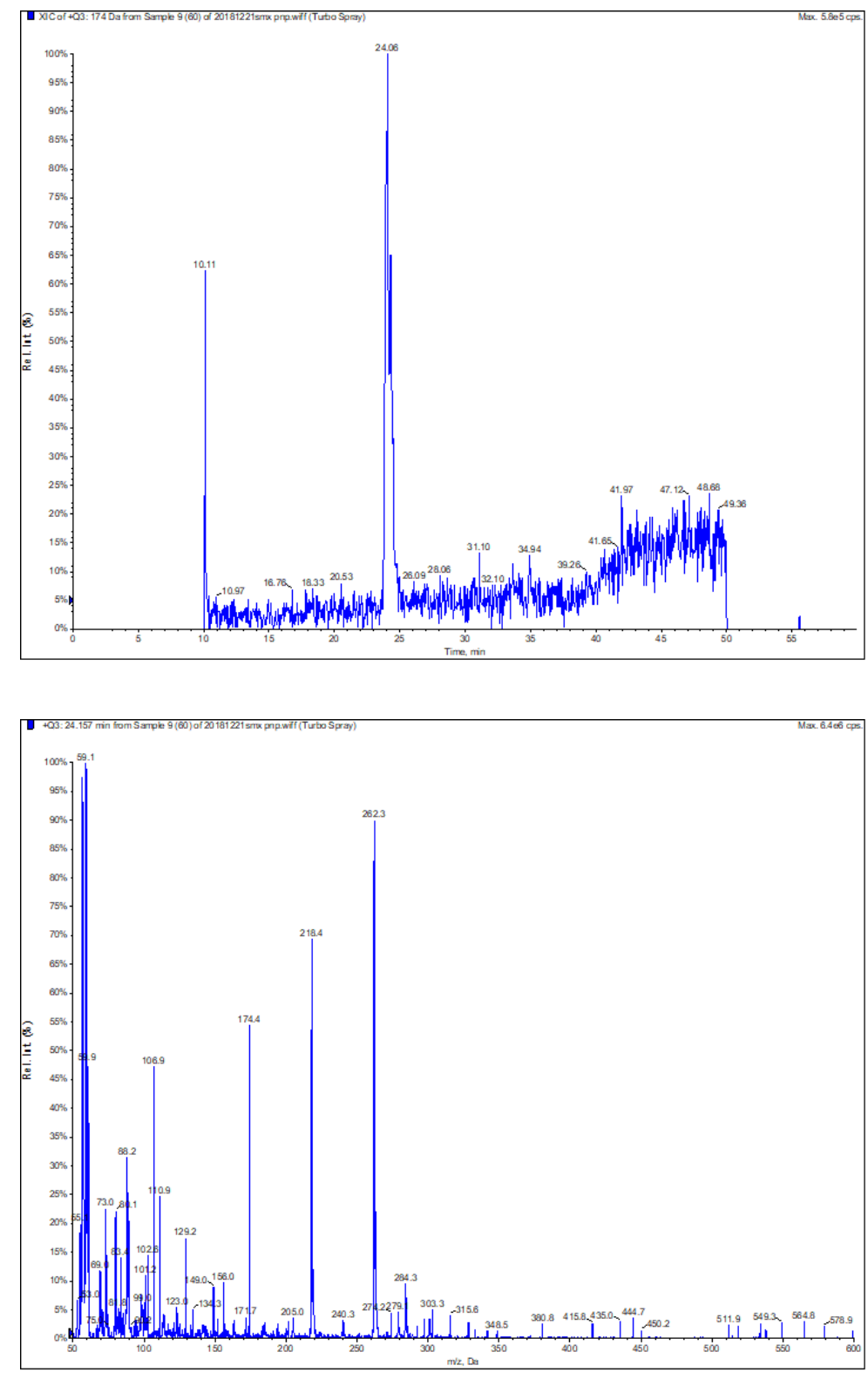

Figure S13. HPLC chromatogram and Mass spectrum of TP 174 identified by HPLC/ESI-QQQ under positive mode in the KMnO4 oxidation of SMX with the presence of biochar. 

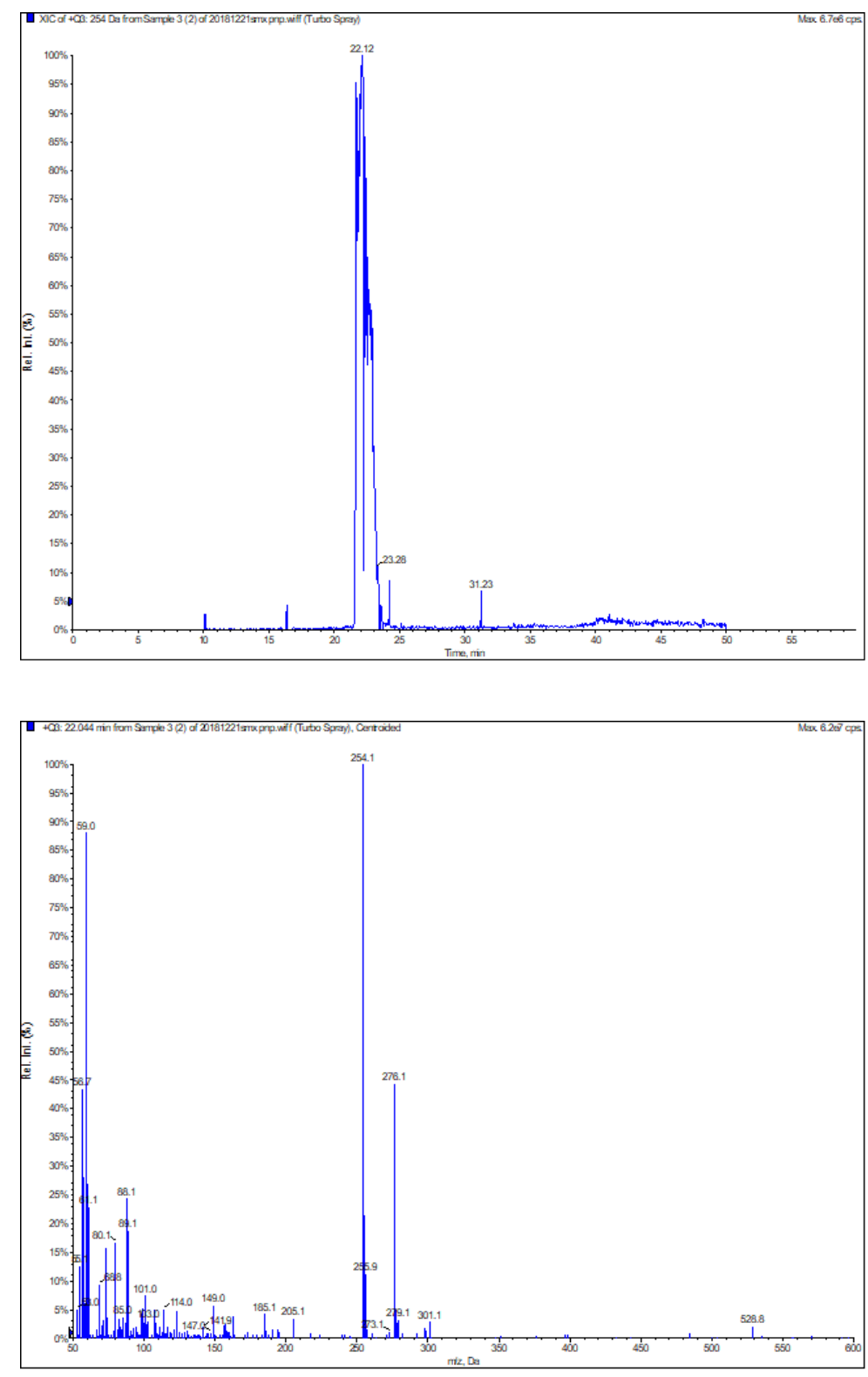

Figure S14. HPLC chromatogram and Mass spectrum of SMX identified by HPLC/ESIQQQ under positive mode in the KMnO4 oxidation of SMX with the presence of biochar. 